Supplement of Hydrol. Earth Syst. Sci., 20, 4605-4623, 2016

http://www.hydrol-earth-syst-sci.net/20/4605/2016/

doi:10.5194/hess-20-4605-2016-supplement

(C) Author(s) 2016. CC Attribution 3.0 License.

(c) (i)

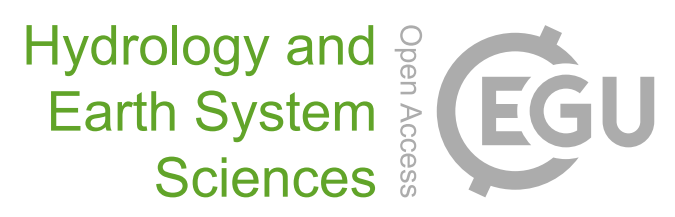

Supplement of

\title{
A statistically based seasonal precipitation forecast model with automatic predictor selection and its application to central and south Asia
}

Lars Gerlitz et al.

Correspondence to: Lars Gerlitz (lars.gerlitz@gfz-potsdam.de)

The copyright of individual parts of the supplement might differ from the CC-BY 3.0 licence. 


\section{Supplements:}

\section{Northern CA}

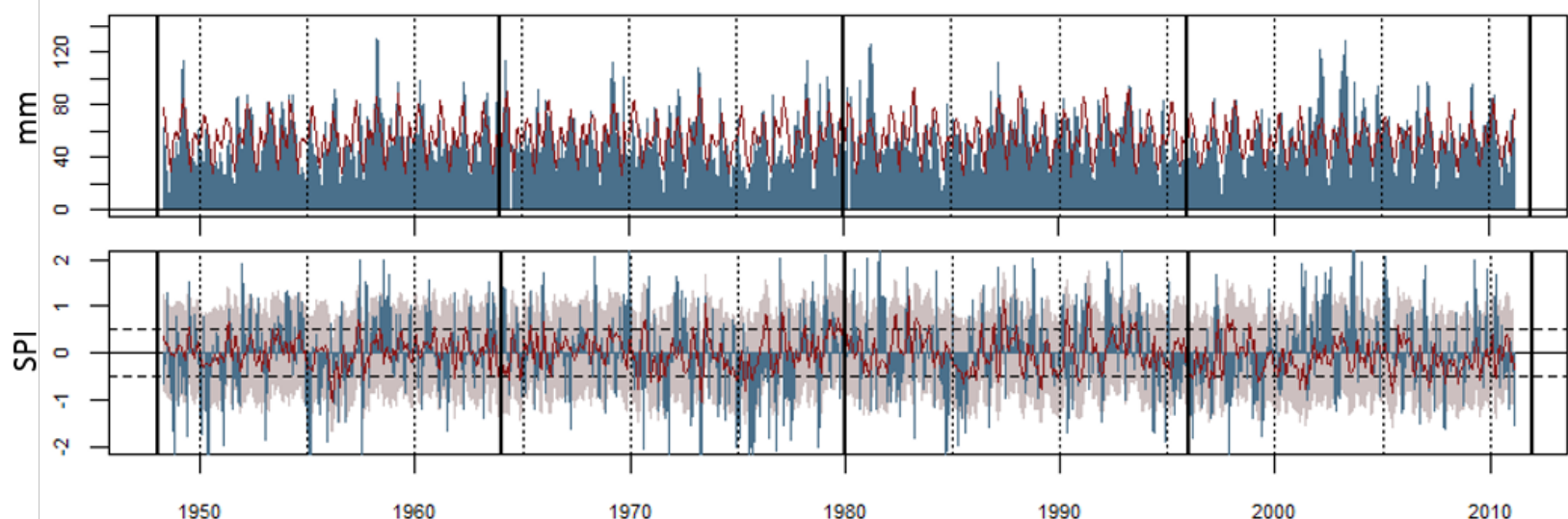

Southern CA
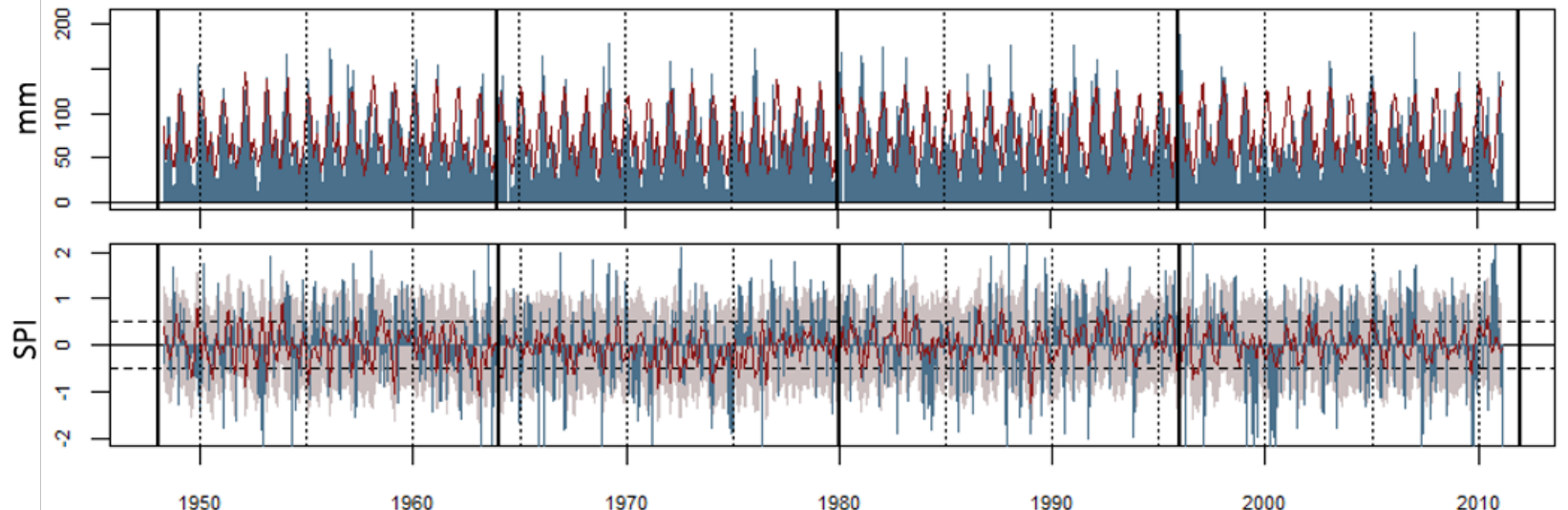

Northern India
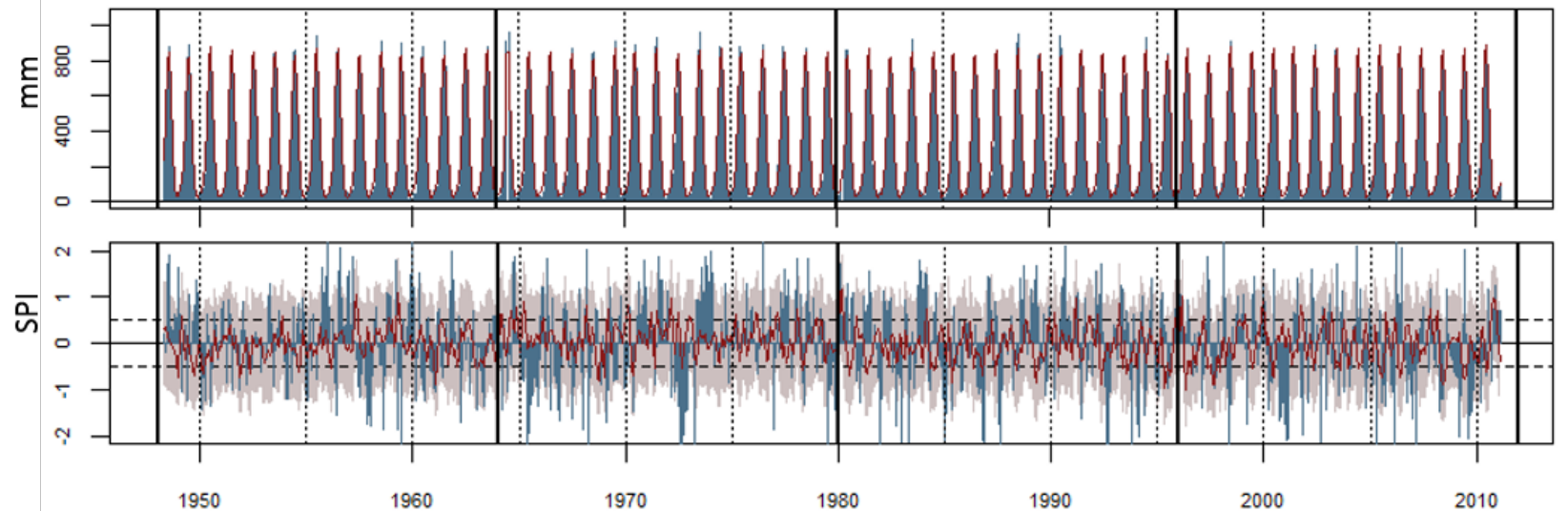

S1: Observed running three-month precipitation totals (blue bars) and modelling results (red line) of the F[4:6] model for selected target regions. The upper panels show absolute precipitation totals for running three-month periods, the lower panel show the corresponding SPI index for each three-month period respectively. Shaded areas indicate the $90 \%$ interval of the residual based probabilistic forecast. Black verticals indicate the division of the time series into four independent evaluation samples. 


\section{Northern CA}
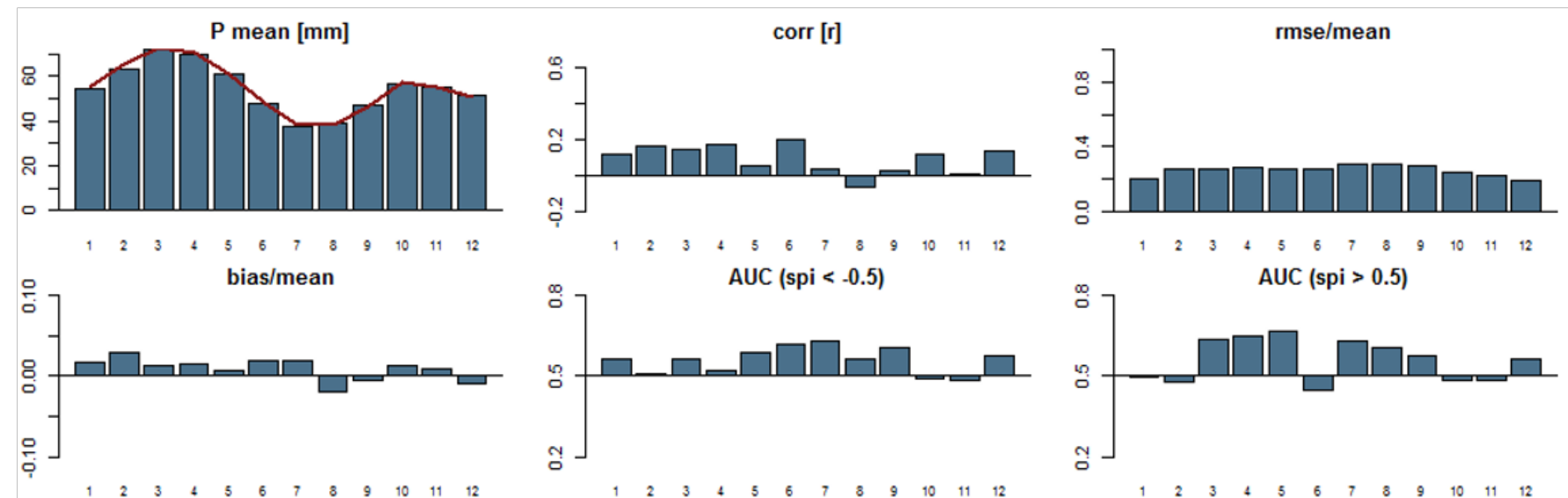

\section{Southern CA}
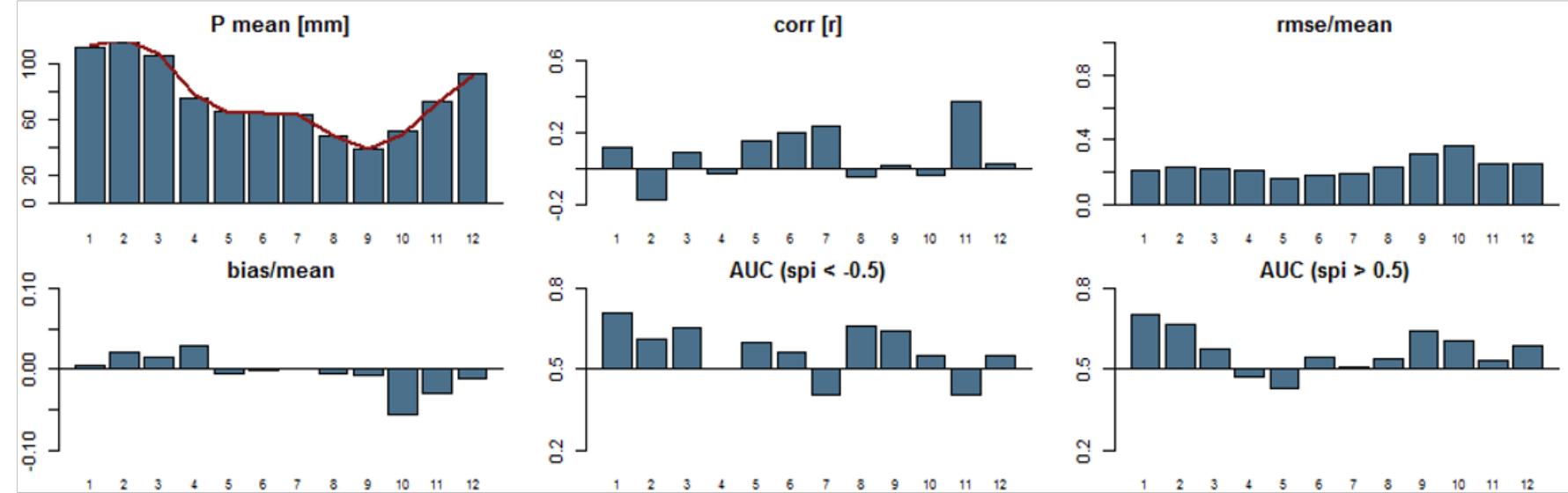

\section{Northern India}
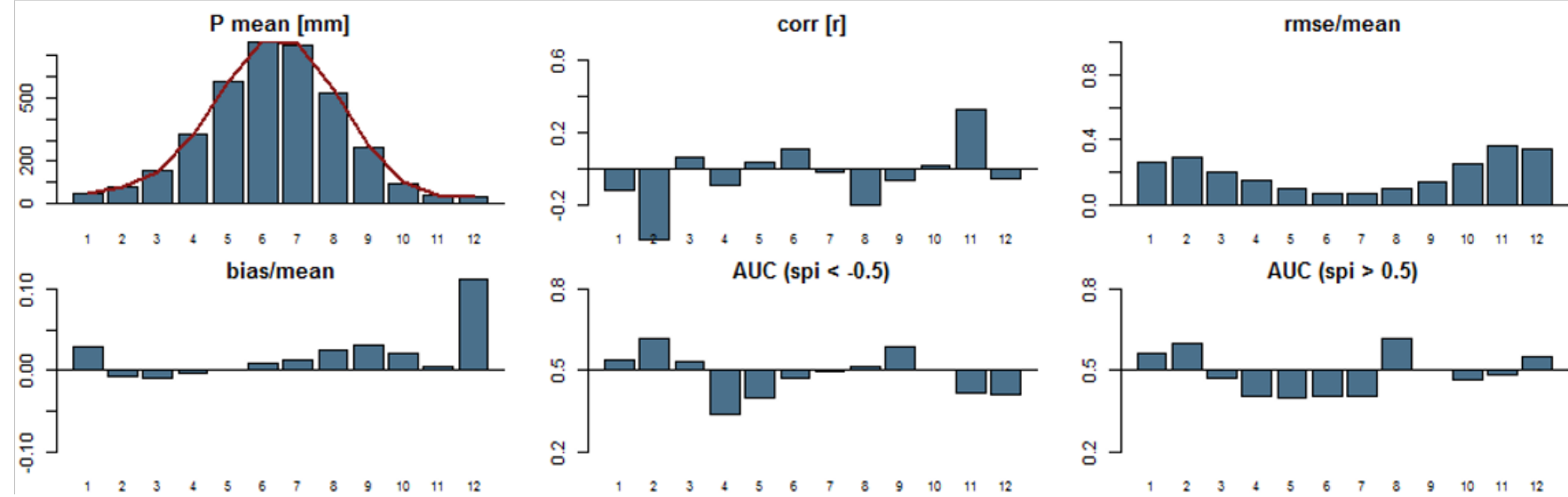

S2: Summary of evaluation measures of the F[4:6] forecast for selected target areas. In order to keep the annual cycle of precipitation amounts, the specified month at the $x$-axis indicate the middle of the forecast period. 